\title{
Construction of Safety Evaluation System of Jacking Form Work System Based on Human Factor Theory
}

\author{
Shilong $\mathrm{Jia}^{1,{ }^{1},}, Y u$ Wang $^{1}$, Zhaofeng Zhang ${ }^{2}$. \\ ${ }^{1}$ School of Civil Engineering, Shenyang Jianzhu University, Shenyang, 110168, China. \\ ${ }^{2}$ Northeast Company of China Construction Third Engineering Bureau Co., Ltd, Shenyang, 110179, China.
}

\begin{abstract}
The jacking form work is a complex system of construction environment, which is extremely important for human factors control. Establishing a harmonious man-machine-environment relationship is of great help to reduce the construction risk of jacking form work. This paper will establish the evaluation indicators which affecting man-machine-environment system balance. Then the AHP-Fuzzy evaluation method was used to carry out comprehensive evaluation. Finally, the real-life project was taken as an example to evaluate the construction safety level. The result can provide an important direction for construction safety management.
\end{abstract}

\section{Introduction}

In recent years, ultra-high-rise buildings are all over the world, and the skylines are constantly being refreshed. The intelligent jacking steel frame of ultra-high-rise building (also name as the jacking form work) is the main construction method of the ultra-high-rise core tub.

The intelligent construction equipment integrated platform (also name as the integrated platform) is the latest generation jacking form work system which is called "Air building machine"[1].

The development of the jacking form work system greatly resolved the problem of the huge structure, large volume, and limited construction sites ${ }^{[2]}$. Jacking form work has gone through four generations. After every innovation, the stability and turnover of jacking form work have been greatly improved. The development of jacking form work construction technology is more and more mature, but the research on safety management is not deep enough.

The environment of jacking form work is a typical man-machine-environment system. Many people think that the accidents can be reduced when the reliability of mechanical equipment is improved, but this idea ignores the role of "human" in the system. According to the theory of human factors engineering, the safety management should pay attention to the human factors. According to Heinrich's " $88: 10: 2$ " rule, $80 \%$ of accidents are caused by human factors ${ }^{[3]}$. In such highly mechanized environment on jacking form work, the safety of construction workers' operation is particularly important.

Therefore, this paper will analyze the construction environment of the jacking form work system based on the human factors, and identify the factors that are easy to disrupt the balance of man-machine-environment system. This paper will also construct a scientific evaluation index system and fulfill the objective evaluation for the safety of jacking form work construction environment.

\section{The Summarize of Integrated Platform}

The jacking form work is a construction technology of high-rise building. It is different from traditional construction model. The jacking form work can integrate various mechanical equipment, supporting facilities, operation platform, protective facilities and intelligent monitoring into platform, and provide different construction platform for the different professional processes at the same time, and realize synchronous lifting ${ }^{[4]}$

The jacking form work can not only normalize and standardize the construction, but also greatly shorten the construction period and save the construction cost. This advanced construction technique has been widely used through the country, such as the project of Beijing CITIC Tower and Wuhan Greenland Center.

At present, most scholars focus on the mechanical properties of jacking form work. There are few studies on safety management. But safety management is important for the development of jacking form work. The purpose of safety management is to protect the safety of worker and equipment, prevent casualties and equipment accidents, protect the state and collective property from loss, and ensure the normal progress of production and construction. Therefore, it is necessary to study the safety management of jacking form work.

\footnotetext{
* Corresponding author: cesljia@sjzu.en.cn
} 


\section{Establishment of Evaluation Model of Jacking Form Work System Based on Human Factors Engineering Theory}

\subsection{Evaluation Index System}

If any human being is participated in the activities, it is known as man-machine-environment system. Therefore, human factors, machine factors, environment factors are first considered when established indicators in this paper. Human are the most important factors in all production activities. There are great differences in different people's psychological and physiological states. It is significant to fully mobilize their factors for the protection of construction safety ${ }^{[5]}$.
Good mechanical environment can meet the operational needs of people to achieve harmonious coexistence of man-machine and improve production. A comfortable working environment not only provide a good basic storage environment of construction machine but also improve the working efficiency of construction workers. Considering the complexity of the jacking form work, the strength index of materials is strictly required during construction, so the factors of materials is also taken as the index content. Finally, strict organization and management is an important reason to determine whether a project can be completed on time with good quality and quantity. Therefore, it is also an important factor in the evaluation. The established safety evaluation index of the jacking form work is shown in Fig.1.

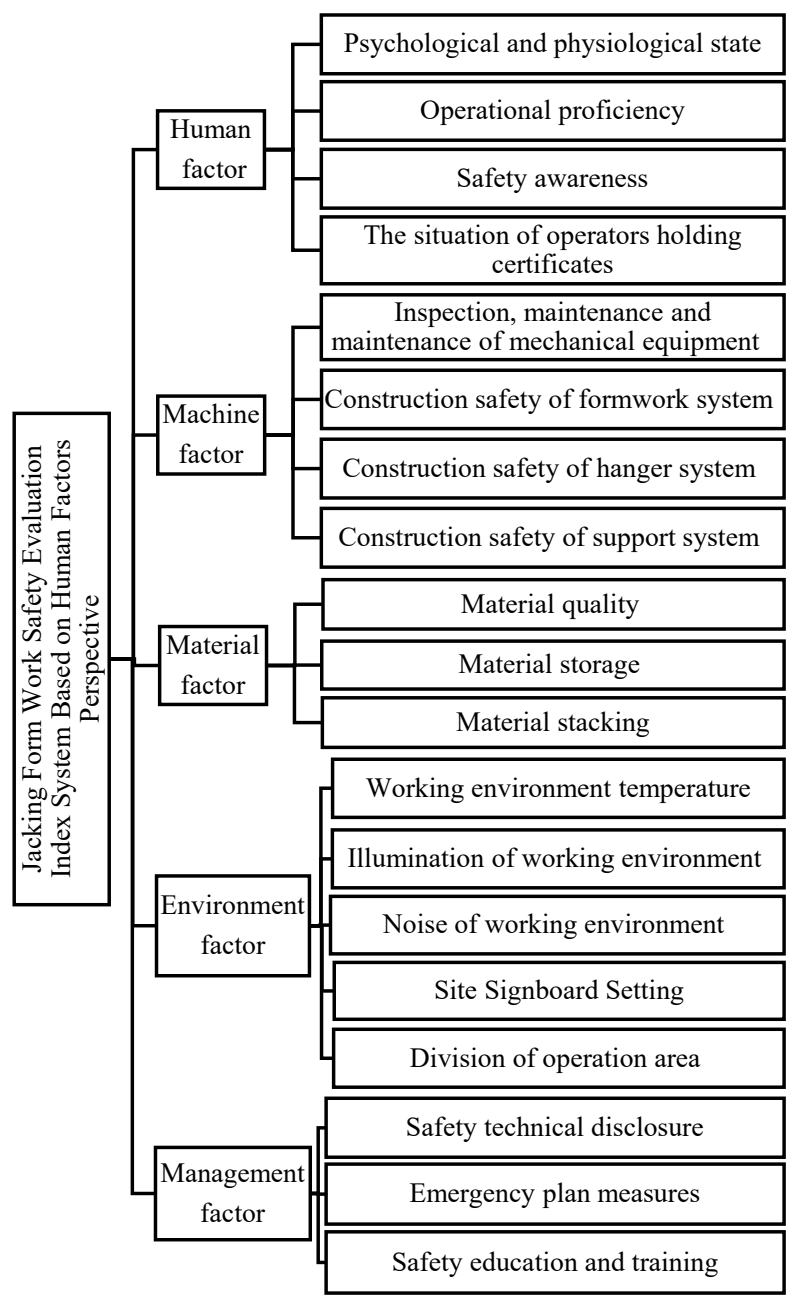

Fig.1. Jacking Form Work Safety Evaluation Index System Based on Human Factors Perspective.

\subsection{Determine the Set of Evaluation Factors}

The evaluation factor set is the total of evaluation indexes. Since the construction safety evaluation indexes of the jacking form work are multi-factor, multi-variable and multi-level, the evaluation set has hierarchy, namely:

$$
\begin{gathered}
\boldsymbol{U}=\left\{u_{1}, u_{2}, \cdots, u_{m}\right\} \\
\boldsymbol{U}_{\boldsymbol{i}}=\left\{\boldsymbol{u}_{\boldsymbol{i 1}}, \boldsymbol{u}_{\boldsymbol{i} 2}, \cdots, \boldsymbol{u}_{\boldsymbol{i n} \boldsymbol{i}}\right\} \boldsymbol{i}=\mathbf{1}, \mathbf{2} \cdots, n_{i}
\end{gathered}
$$

Where, $m$ denotes the number of factors in $U$, $n_{i}$ denotes the number of factors in $U_{i}$.

\subsection{Determine Weight of Indicator Hierarchy}

The weight of evaluation factors indicates the importance of each factors in the set.

$$
\boldsymbol{A}=\left\{a_{1}, a_{2}, \cdots, a_{m}\right\}
$$




$$
\boldsymbol{A}_{\boldsymbol{i}}=\left\{a_{i 1}, a_{i 2}, \cdots, a_{i n_{i}}\right\} \boldsymbol{i}=\mathbf{1}, 2 \cdots, n_{i}
$$

Where $A_{i}$ denotes the weight of factors in A.

The weight is determined by Analytic hierarchy process, and the factors $U$ of the same layer belonging to each factor of the previous layer are compared in pairs according to 1-9 proportion scale to form a judgment matrix $R$.

Table 1. Importance degree calculation

\begin{tabular}{|c|c|}
\hline Scale & Relative importance \\
\hline 1 & Equally important \\
\hline 3 & A little more important \\
\hline 5 & More important \\
\hline 7 & Much more important \\
\hline 9 & Rather more important \\
\hline $2,4,6,8$ & $\begin{array}{c}\text { Relative importance lying between adjacent } \\
\text { scales; } a_{i j}=\frac{1}{a_{j i}}\end{array}$ \\
\hline
\end{tabular}

Find the maximum eigenvalue of $R$ to obtain the weight sets of each level respectively and calculate the consistency index $C I$ and random consistency ratio $C R$ according to Equation (5) and Equation (6).

When $C R<0.10$, the judgment matrix is considered to have satisfactory consistency, otherwise the judgment matrix needs to be adjusted ${ }^{[6]}$.

$$
\begin{gathered}
\boldsymbol{C I}=\frac{\lambda_{\max }-n}{n-a} \\
\boldsymbol{C} \boldsymbol{R}=\frac{C I}{R I}
\end{gathered}
$$

Where, $R I$ is average consistency index (table 2).

Table 2. Average consistency index

\begin{tabular}{|c|c|c|c|c|c|c|c|}
\hline $\begin{array}{c}\text { Matrix } \\
\text { order }\end{array}$ & 3 & 4 & 5 & 6 & 7 & 8 & 9 \\
\hline$R I$ & 0.58 & 0.90 & 1.12 & 1.24 & 1.32 & 1.41 & 1.46 \\
\hline
\end{tabular}

\subsection{Determine the Set of Comments}

Comments set is a set of various general evaluation results that the evaluator may make to the evaluation object. The evaluation grade is safe, relatively safe, critical, dangerous and very dangerous. The comment set $V$ represents comments at all levels from high to low.

$$
\boldsymbol{V}=\left\{v_{1}, v_{2}, \cdots, v_{n}\right\}
$$

\subsection{Determine the Index Evaluation Matrix}

The fuzzy comprehensive evaluation index matrix is to statistically determine the grade distribution rate according to the evaluation results of the evaluators, and each evaluation object corresponds to a comprehensive evaluation matrix $R$.

$$
R=\left[\begin{array}{ccc}
r_{11} & \cdots & r_{1 n} \\
\vdots & \ddots & \vdots \\
r_{i 1} & \cdots & r_{i n}
\end{array}\right]
$$

\subsection{Comprehensive Evaluation}

Firstly, the fuzzy comprehensive evaluation is made on the second-level evaluation factor $U_{i}$, and the comprehensive evaluation level $B_{i}$ is obtained as follows:

$$
B_{i}=A_{i} \cdot R_{i}
$$

Then, $m$ factors of the fist-level factor $U$ are comprehensive evaluated to obtain the comprehensive evaluated level:

$$
B=A \cdot R
$$

\section{Empirical Analysis}

In this paper, an ultra-high-rise building with a height of 568 meters, a total of 119 floors and a building area of 339000 in Shenyang is taken as an example. The construction technology of this project is the fourth generation jacking form work: The intelligent construction equipment integrated platform.

The integrated platform not only has the advantage of previous generations but has also been made some modifications and innovations. The integrated platform is the first system which the construction tower is integrated into platform and realizes synchronous lifting. In this project, the integrated platform integrated three tower cranes (ZSL2700/M1280D/ZSL1150) ${ }^{[7]}$.

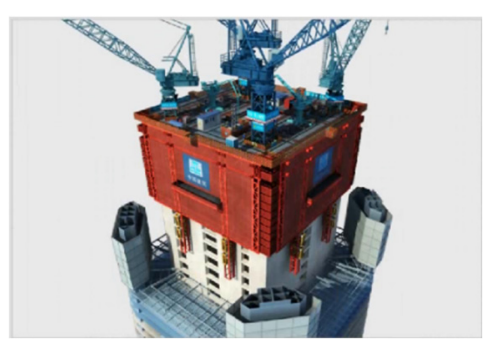

Fig. 2. Integrated Platform 3D Model

The above AHP-Fuzzy evaluation model is applied to comprehensively evaluate the safety of the integrated platform construction from the perspective of human factors.

According to the determined evaluation index, the evaluation factor sets can be obtained as table 3 . The integrated platform safety evaluation index system based on human factors perspective as the target layer $U$.

Table 3. Evaluation index system $U$.

\begin{tabular}{|c|l|}
\hline $\begin{array}{c}\text { Standard } \\
\text { layer }\end{array}$ & \multicolumn{1}{|c|}{ Scenario layer } \\
\hline \multirow{2}{*}{$\begin{array}{c}\text { Human } \\
\text { factor } \\
U_{1}\end{array}$} & $\begin{array}{l}\text { Psychological and physiological } \\
\text { state } u_{11}\end{array}$ \\
\cline { 2 - 2 } & Operational proficiency $u_{12}$ \\
\hline
\end{tabular}




\begin{tabular}{|c|c|}
\hline & Safety awareness $u_{13}$ \\
\hline & $\begin{array}{l}\text { The situation of operators holding } \\
\text { certificates } u_{14}\end{array}$ \\
\hline \multirow{4}{*}{$\begin{array}{l}\text { Machine } \\
\text { factor } \\
U_{2}\end{array}$} & $\begin{array}{l}\text { Inspection, maintenance and } \\
\text { maintenance of mechanical equipment } \\
u_{21}\end{array}$ \\
\hline & $\begin{array}{l}\text { Construction safety of form work } \\
\text { system } u_{22}\end{array}$ \\
\hline & $\begin{array}{l}\text { Construction safety of hanger system } \\
u_{23}\end{array}$ \\
\hline & $\begin{array}{l}\text { Construction safety of support } \\
\text { system } u_{24}\end{array}$ \\
\hline \multirow{3}{*}{$\begin{array}{l}\text { Material } \\
\text { factor } \\
U_{3}\end{array}$} & Material quality $u_{31}$ \\
\hline & Material storage $u_{32}$ \\
\hline & Material stacking $u_{33}$ \\
\hline \multirow{5}{*}{$\begin{array}{l}\text { Environment } \\
\text { factor } \\
U_{4}\end{array}$} & $\begin{array}{l}\text { Working environment temperature } \\
u_{41}\end{array}$ \\
\hline & $\begin{array}{l}\text { Illumination of working } \\
\text { environment } u_{42}\end{array}$ \\
\hline & Noise of working environment $u_{43}$ \\
\hline & Site Signboard Setting $u_{44}$ \\
\hline & Division of operation area $u_{45}$ \\
\hline \multirow{3}{*}{$\begin{array}{l}\text { Management } \\
\text { factor } \\
U_{5}\end{array}$} & Safety technical disclosure $u_{51}$ \\
\hline & Emergency plan measures $u_{52}$ \\
\hline & Safety education and training $u_{53}$ \\
\hline
\end{tabular}

A pairwise comparison matrix is established for each level index, and the maximum eigenvalue of each matrix and the normalized vector corresponding to the eigenvalue are calculated by Matlab programming, and the consistency test is done to obtain the weight set. Results as shown in the table, the random consistency ratio $C R<0.10$.

The safety evaluation level of the integrated platform is divided into five levels: safe $\left(v_{1}\right)$, relatively safe $\left(v_{2}\right)$, critical $\left(v_{3}\right)$, dangerous $\left(v_{4}\right)$, very dangerous $\left(v_{5}\right)$.

\subsection{Evaluation Matrix}

In order to establish the matrix, this paper invites ten experts with rich construction experience and safety evaluation experience of jacking form work system. According to expert scoring method to determine the degree of membership matrix.

$$
R_{1}=\left[\begin{array}{ccccc}
0 & 0.4 & 0.6 & 0 & 0 \\
0.2 & 0.4 & 0.4 & 0 & 0 \\
0 & 0.5 & 0.3 & 0.2 & 0 \\
0.7 & 0.3 & 0 & 0 & 0
\end{array}\right]
$$

$$
\begin{gathered}
R_{2}=\left[\begin{array}{lllll}
0.8 & 0.2 & 0 & 0 & 0 \\
0.6 & 0.5 & 0 & 0 & 0 \\
0.3 & 0.7 & 0 & 0 & 0 \\
0.8 & 0.2 & 0 & 0 & 0
\end{array}\right] \\
R_{3}=\left[\begin{array}{ccccc}
0.6 & 0.4 & 0 & 0 & 0 \\
0.1 & 0.7 & 0.2 & 0 & 0 \\
0.2 & 0.7 & 0.1 & 0 & 0
\end{array}\right] \\
R_{4}=\left[\begin{array}{ccccc}
0.3 & 0.5 & 0.2 & 0 & 0 \\
0 & 0.3 & 0.4 & 0.3 & 0 \\
0 & 0.2 & 0.5 & 0.2 & 0.1 \\
0.2 & 0.5 & 0.3 & 0 & 0 \\
0.3 & 0.4 & 0.3 & 0 & 0
\end{array}\right] \\
R_{5}=\left[\begin{array}{ccccc}
0.3 & 0.4 & 0.3 & 0 & 0 \\
0 & 0.7 & 0.3 & 0 & 0 \\
0.2 & 0.6 & 0.2 & 0 & 0
\end{array}\right]
\end{gathered}
$$

\subsection{Fuzzy Comprehensive Evaluation}

The evaluation matrix $R=\left\{R_{1}, R_{2}, \cdots, R_{m}\right\}$ is normalized by standard method, and then fuzzy comprehensive evaluation is carried out to obtain the evaluation results. According to the formula (9), it can be obtained:

$$
\begin{gathered}
B_{1}=[0.3677,0.3533,0.2156,0.0273,0] \\
B_{2}=[0.6685,0.3425,0,0] \\
B_{3}=[0.4217,0.5219,0.0564,0,0] \\
B_{4}=[0.2101,0.3912,0.3326,0.0511,0.0150] \\
B_{5}=[0.1534,0.6093,0.2373,0,0]
\end{gathered}
$$

According to the principle of maximum membership degree of fuzzy comprehensive grade is $v_{1}$, which is in a safe state. By the same token, $B_{2}$ is in a safe state, and $B_{3}$ is in a relatively safe state, and $B_{4}$ is in a relatively safe state, and $B_{5}$ is in a relatively safe state.

Based on the data obtained above, the fuzzy matrix $Y$ of the target layer can be obtained.

$$
Y=[0.5638,0.3867,0.0465,0.0042,0]
$$

According to the principle of maximum membership, the integrated platform construction project is in a safe state.

\section{Conclusion}

The fuzzy analytic hierarchy process was applied to the construction safety evaluation of integrated platform, and the evaluation index at the fuzzy boundary is quantified to judge the degree of safety control by the construction unit in the construction project of integrated platform. Through the evaluation and application of the actual project, it can be understood that the construction materials, environment and management of the project should be further strengthened during the platform construction, so as to realize the harmonious matching 
between the integrated platform and people, improve the construction safety, and lay a solid foundation for the future scientific development of the integrated platform.

\section{Acknowledgements}

The authors wish to thank Science and technology program of the Educational Department of Liaoning Province, China (lnjc201905) for sponsoring this research project.

\section{References}

1. C.L Pan, W.B Quan, W.S Zhang. Technical of the Equipment Integrated Platform of High-rise Building [J]. Construction Technology,46.16(2017):1-4+17.

2. J.W Zhu, M.Y Ouyang. Exploring the Construction Technology of Super High-rise Building [J]. Architecture. 20(2018):64-66.

3. H.L Yu. Risk Analysis and Evaluation of Construction Safety based on Human Factors [D]. Huazhong University of Science and Technology, (2010).

4. C.L Pan. Technical of Equipment Integrated Platform of High-rise Building. Construction Technology, 46.16(2017): $1-5+17$.

5. X Chen, S.Z Long. Overview of Man-MachineEnvironment System Engineering $[\mathrm{J}]$. Nature, 01(1985):36-38+80.

6. S.Y Sheng. Study on Construction Quality Evaluation of Construction Engineering based on Fuzzy Analytical Hierarchy Process [J]. Sichuan Building Material.,44.11(2018):216-217.

7. C.L Pan, S.M Chen, G.F Wang. Construction Technology of Building Structure Under Construction Condition of Integration Platform for Shenyang Baoneng Global Financial Center Project. Construction Technology,46.16(2017):18-20. 